\title{
The Use of Traits and Contextual Information in Free Personality Descriptions across Ethnocultural Groups in South Africa
}

\author{
Velichko H. Valchev \\ Tilburg University, The Netherlands \\ Fons J. R. van de Vijver \\ Tilburg University, The Netherlands, North-West University, South Africa, and University of \\ Queensland, Australia \\ J. Alewyn Nel \\ North-West University, South Africa \\ Sebastiaan Rothmann \\ North-West University, South Africa \\ Deon Meiring \\ University of Pretoria, South Africa \\ To appear in the Journal of Personality and Social Psychology \\ - This is an unedited manuscript version that has been accepted for publication. \\ - This manuscript may not exactly replicate the final article version published in the APA journal. It is \\ not the copy of record. \\ (C) American Psychological Association \\ Journal home page: http://www.apa.org/pubs/journals/psp/index.aspx
}




\begin{abstract}
The present study investigates the differences between 3 ethnocultural groups in South Africa in the use of traits and contextual information for personality descriptions and the interaction of these differences with social distance from the target person and with personality domains. Semistructured interviews asking for selfand other-descriptions were conducted with 1,027 Blacks, 84 Coloureds and Indians, and 105 Whites, representing the country's 11 official languages. In Part 1 we found similarities in the total set of categories used most often for personality description across the 3 groups - traits, behaviors, preferences, and perceptions (over 86\%), which were context-free (over 66\%) - as well as substantial differences between the groups in the relative use of these categories. In Part 2 we found that distance from the target person plays a role in cross-cultural differences in trait use and contextualization. In Part 3 we found significant interactions of culture with the use of traits and contextual information across agency-communion and 9 indigenous South African personality clusters similar to the Big Five. The responses of Blacks confirmed expectations for collectivistic groups (fewer traits and more contextualization), of Whites for individualistic groups (more traits and less contextualization), and Coloureds and Indians had an intermediate pattern. The results are discussed in the framework of the trait and cultural psychology perspectives on personality.
\end{abstract}

Keywords: trait, context, culture, implicit personality conceptions 
The present study investigates differences between ethnocultural groups in South Africa in the use of traits and contextual information for personality descriptions. The concept of traits as abstract personality characteristics, enduring over time and consistent across situations, is central to personality psychology (John, Naumann, \& Soto, 2008). In the field of cross-cultural personality studies, different perspectives have been taken on the importance of traits for understanding personality. On the one hand, culture-comparative work assumes the importance and applicability of traits across cultures (e.g., McCrae \& Allik, 2002; McCrae, Terracciano, \& 78 Members of the Personality Profiles of Cultures Project, 2005). On the other hand, researchers in more relativistic traditions support the view that traits are more relevant and salient in individualistic cultures, whereas concrete, contextspecific descriptions are more salient in collectivistic cultures (e.g., Shweder \& Bourne, 1984; Triandis, 2001). These perspectives are referred to as trait and cultural psychology, respectively. Their implications and empirical support have been studied systematically in a series of publications by Church and colleagues (Church, 2000, 2009, 2010; Church, Anderson-Harumi, et al., 2008; Church, Katigbak, et al., 2008; Church et al., 2003; Del Prado et al., 2007). In short, there are mixed findings supporting aspects of both perspectives, with a preponderance of support for the trait perspective, especially among non-Asian populations (Del Prado et al., 2007; for reviews of the topic, see also Benet-Martínez \& Oishi, 2008; Church, 2009, 2010; Heine \& Buchtel, 2009; Triandis \& Suh, 2002). The present study aims to contribute to this literature by (a) extending it to the largely understudied African context while employing a more graded than the usual dichotomous approach to individualismcollectivism; (b) addressing the role of social distance for cross-cultural differences; 
and (c) investigating the interplay of these differences with domains of personality, to identify the domains with the most pronounced differences.

This study is divided in three parts. In Part 1, we test for overall cross-cultural differences in the use of traits and other categories of personality description and in contextualization. In Part 2, we address the role of social distance from the described person. In Part 3, we turn to a little studied aspect of cross-cultural differences in personality descriptions: We investigate traits and contextualization across personality domains defined both in broad terms like agency and communion, and in more specific terms of personality clusters. In the remainder of the introduction, we delineate the theoretical frameworks relevant for the questions of each of these parts. We conclude the introduction with a section on the cultural characteristics of subpopulations in South Africa.

\section{Traits and Contextualization across Cultures}

The different views on traits across cultures can be represented using the contraposition of the trait and cultural psychology perspectives. The development of universal personality models like the Big Five (John et al., 2008) is based on the assumption of the trait perspective that traits have a central meaning for the conceptions of personality across cultures. This assumption allows researchers in the psycholexical approach to study selections of traits by sampling trait terms from a language's lexicon (Allport \& Odbert, 1936; Saucier \& Goldberg, 2001). The existence of trait terms in all languages has been taken to support the validity of traitbased personality models (Del Prado et al., 2007; Saucier \& Goldberg, 2001). On the other hand, there is a substantial body of literature in cultural psychology pointing to cross-cultural differences in the use of traits for describing and conceptualizing personality. The cultural psychology perspective is closely associated with the 
individualism-collectivism theoretical framework. People in collectivistic cultures, as opposed to those in individualistic cultures, tend to describe personality and behavior less in abstract trait terms and more in terms of specific behaviors embedded in specific contexts, and in terms of social roles and identities (Markus \& Kitayama, 1998). Such differences have been documented most widely for self-descriptions using open-ended measures like the Twenty Statements Test (TST) where participants are asked to complete the sentence "I am..." up to 20 times (e.g., Cousins, 1989; Rhee, Uleman, Lee, \& Roman, 1995), but also using other methods and target persons (Del Prado et al., 2007). There is also a line of research that has demonstrated crosscultural differences in causal attributions, where people in collectivistic cultures, as opposed to those in individualistic cultures, tend to attribute behaviors more strongly to situational rather than dispositional (that is, trait) factors (Choi, Nisbett, \& Norenzayan, 1999). Cross-cultural differences in trait use have implications varying from implicit personality conceptions, through trait beliefs and causal attributions, to actual temporal and cross-situational behavior consistency and predictability from traits (Church, 2000, 2009). Our study focuses on the first of these topics, personality conceptions.

Cross-cultural differences in contextualization can be placed in the same framework as differences in trait use: People in collectivistic cultures are more sensitive than those in individualistic cultures to relational and situational contexts (Church, 2000; Markus \& Kitayama, 1998; Nisbett, Peng, Choi, \& Norenzayan, 2001). Two main aspects of the interplay of personality and context can be distinguished. The first aspect refers to the question: How does context influence selfconcepts and behavior across cultures? There is evidence that self-concepts as well as particular perceptions and behaviors vary with context more widely in collectivistic 
than in individualistic cultures (Cousins, 1989; Kanagawa, Cross, \& Markus, 2001; Oishi, Diener, Scollon, \& Biswas-Diener, 2004). The second aspect refers to the question: What is the perceived role of context for implicit personality conceptions? This is the aspect addressed in the present study. In most approaches to this question, traits and context are treated as opposites: Person conceptions can be more "traited" (stable, consistent) or more "contextualized" (situationally defined; Church, 2009; Heine \& Buchtel, 2009). In some recent approaches, however, trait use and contextualization are treated as theoretically and empirically distinct concepts (Kashima, 2001; Kashima, Kashima, Kim, \& Gelfand, 2006). Contextualized references involve relations, situations, or other kinds of context to describe personality, which can be used both for traits and behaviors. For example, "she is kind" is a context-free trait description and "she is kind to her neighbors" is a relationally qualified trait description, as it describes a target of the kindness; "she helps" is a context-free behavior description and "she helps her neighbors" is a relationally qualified behavior description. Similarly, "she is kind when you do not discuss money" is a situationally qualified trait description and "she helps when you are sick" is a situationally qualified behavior description. The present study independently assesses the use of both traits and context for implicit personality conceptions across groups.

Del Prado and colleagues (2007) noted that, despite the generality of cultural psychology's claims on cross-cultural differences, most support has come from comparisons of European and East Asian (mostly student) populations, whereas studies of other groups presumably differing on the individualism-collectivism dimension have failed to provide such support. This has led researchers to speculate that cross-cultural differences in trait use could be attributable to some specific Asian 
characteristics such as holistic or dialectical thought with its acceptance of contradiction, complexity, and change, rather than to individualism-collectivism (Church, 2009; Del Prado et al., 2007; Kashima et al., 2006); yet, this speculation has received moderate support (Church, 2009). Very little research on personality and trait use has been conducted in Africa and with non-student or illiterate populations (Church, 2010; Del Prado et al., 2007; Van de Vijver \& Leung, 2001). Africans have been found to endorse collectivistic aspects of the self more strongly than people of European descent (Ma \& Schoeneman, 1997; Watkins et al., 1998). The present study aims to enrich this literature by investigating personality concepts in community samples from different cultural groups in South Africa.

In Part 1, we address two questions: (a) to what extent there are differences, predicted from the cultural psychology perspective, in the use of traits and contextualizing information in personality descriptions in the main ethnocultural groups of South Africa, and (b) which specific non-trait and contextualization categories are used.

\section{Traits and Contextualization across Social Distance}

Cross-cultural differences in trait use have been interpreted as resulting from different conceptions of the self or of the person in general (Kashima, 2001). In the self-concept interpretation (Markus \& Kitayama, 1998; Triandis, 2001), individuals in different cultures develop different concepts of the self-focusing more on internal attributes or on interpersonal and situational information—and subsequently transfer this conception to persons in general. In the broader person-concept interpretation (Shweder \& Bourne, 1984), individuals develop different personality conceptions that do not distinguish between self- and other-concepts. There is evidence that selfperceptions differ from perceptions of others, whereby social distance plays a role and 
distant others are perceived in more global terms than close others and the self (Liberman, Trope, \& Stephan, 2007; Pronin, 2008). These different theoretical perspectives would lead to different predictions on the use of traits for self- and otherdescriptions across cultures. In addition, social distance could affect not only trait use but also contextualization. An examination of the effects for both trait use and contextualization is needed to assess their overlap and relative contribution to crosscultural differences in personality descriptions (Kashima et al., 2006). We examine the effects of social distance from the described person in Part 2.

\section{Traits and Contextualization across Personality Domains}

Some studies have considered how self-descriptions differ across cultures in terms of agentic versus communal elements (Del Prado et al., 2007) or the Big Five model (Watkins \& Gerong, 1997). It has been found that agentic self-descriptions, referring to personal effectiveness, are used more frequently by people from individualistic cultures, and communal self-descriptions, referring to social connection and harmony, by people from collectivistic cultures (Del Prado et al., 2007; see also Bakan, 1966; Sedikides, Gaertner, \& Vevea, 2005). So, from a crosscultural perspective, differences not only in the use of traits, but also in the semantic content of personality descriptions are interesting. However, the intersection of the two research areas has blind spots. Are traits used equally often for different personality domains, and does that differ across cultures? To our knowledge, there are no empirical data in the literature to answer this question, although it has important implications. From the perspective of research on trait use, an interaction between culture, trait use, and personality dimensions would identify more clearly the areas where the trait or cultural psychology approach is better applicable. From the perspective of research on personality structure, the investigation of this interaction 
would identify the personality dimensions that are more likely to be affected by different questionnaire item formulations (using abstract terms vs. concrete behaviors) across cultures.

A promising approach to tackle the interaction of trait use, personality domain, and culture can be derived from work on the psycholexical hypothesis; this hypothesis states that the most important personality characteristics become encoded in language as single, abstract terms which are used frequently (Saucier \& Goldberg, 2001). Communal characteristics are perceived as more important in collectivist cultures and hence traits may be used more often to express them. On the other hand, communal characteristics may tend to be expressed more often with behaviors rather than traits because behaviors are better suited to describe relations (De Raad, 1999). It can hence be expected that, after taking into account the main effect of cross-cultural differences in agentic and communal descriptions and trait use, people in more collectivistic groups use relatively more traits for communal descriptions, and those in more individualistic groups use relatively more traits for agentic descriptions.

The interplay of personality and context has also attracted renewed interest (e.g., Donnellan, Lucas, \& Fleeson, 2009; Funder, 2008; Mischel \& Shoda, 1995), with some moves to incorporate culture in this interplay (e.g., Church, Katigbak, \& Del Prado, 2010; Matsumoto, Yoo, Fontaine, \& 56 Members of the Multinational Study of Cultural Display Rules, 2009; Mendoza-Denton \& Mischel, 2007; Oishi et al., 2004). Still, there is no unified account of the role of context for personality across cultures (e.g., the role of context for the way certain personality dimensions are expressed). There is evidence that the effect of adding contextual information on interjudge agreement differs across personality dimensions (De Raad, Sullot, \& Barelds, 2008). However, it is less clear to what extent spontaneous personality 
descriptions along these dimensions show contextualization, and whether this usage differs across cultures. This is an important question because it refers to the perceived situatedness of personality functioning in different domains. It also has a bearing on the relation between traits and context: If trait use and contextualization are opposites, their patterns should mirror each other across personality dimensions. No such mirror patterns would be expected if trait use and contextualization are relatively distinct. We address cross-cultural differences in trait use and contextualization across personality domains in Part 3.

\section{The South African Context}

South Africa has a remarkable cultural diversity. There are 11 official languages, belonging to two language families: nine Bantu languages (Northern Sotho, Southern Sotho, and Tswana in the Sotho-Tswana group; Ndebele, Swati, Xhosa, and Zulu in the Nguni group; Tsonga, and Venda), spoken by $77.9 \%$ of the population, and two Germanic (Afrikaans and English), spoken as a first language by $21.5 \%$ of the population. The Apartheid-era distinction of four "ethnic" groups is still in use today, namely "Black" (for people of African descent), "Coloured" (mixed-race descent), "Indian" (or “Asian," for descendants of immigrants from India and SouthEast Asia), and "White" (European descent). The nine Bantu languages are spoken as first language by people of African descent only. The two Germanic languages are spoken as first language by Whites (9.6\% of the country's population), Coloureds (Afrikaans speakers, 8.9\%), and Indians (English speakers, 2.5\%; Statistics South Africa, 2001).

Even though research is sometimes conducted on the level of the four ethnic groups (Duckitt, Callaghan, \& Wagner, 2005) and recent studies have sought to account for the linguistic diversity of South Africa (Meiring, Van de Vijver, 
Rothmann, \& Barrick, 2005; Nel et al., 2012), studies have most often compared Blacks and Whites. There is evidence for differences between the two groups, which points to Blacks being more collectivistic and Whites more individualistic (Allik \& McCrae, 2004; Eaton \& Louw, 2000; Watkins et al., 1998). A more differentiated approach may be needed: Whereas Whites are more individualistic and Blacks more collectivistic, Coloureds and Indians in South Africa may occupy an intermediate position. This expectation is based on culture-level studies which have shown that individualism-collectivism is associated both with language characteristics (Kashima \& Kashima, 2003) and with socioeconomic indices such as affluence and education (Georgas, Van de Vijver, \& Berry, 2004). Coloureds and Indians share the dominant use of Germanic languages with the White group; however, they have had, for generations, less opportunity for education and socioeconomic development than

Whites but more than Blacks (Seekings, 2008). There are no clear theoretical reasons or empirical data that suggest specific differences between Coloureds and Indians on the studied concepts, despite their different cultural background. It is thus expected that Coloureds and Indians have an intermediate position between Whites and Blacks with respect to individualism-collectivism, and we expect this position to be displayed in the characteristics of their personality descriptions. We refer to the three groups as ethnocultural in recognition of the classification complexity.

\section{Part 1: Overall Effects}

In the first part, we investigate differences in the categories and contextualization of personality descriptions in the three ethnocultural groups. We test the following two hypotheses, derived from the cultural psychology perspective: 
Hypothesis 1: Blacks use the smallest proportion of trait descriptions, and Whites the largest, with Coloureds and Indians taking an intermediate position.

Hypothesis 2: Blacks use the largest proportion of contextualizing information in their personality descriptions, and Whites the smallest, with Coloureds and Indians taking an intermediate position.

With respect to trait use, we also examine the specific categories that make up the non-trait responses to get a better understanding of what other categories are used across groups. With respect to contextualization, we examine to what extent there are cross-cultural differences in the types of contextualization (relational, temporalsituational, life domain, or composite) used more often.

\section{Method}

The data for the present study are part of a large project investigating implicit personality conceptions in South Africa and aiming at the development of a new, indigenously-derived inventory, the South African Personality Inventory (SAPI; see Nel et al., 2012; Valchev et al., 2011, in press). All analyses reported here were performed on different parts of the same database.

Participants. Interviews were conducted with 1,216 participants from the 11 language groups in their first language. A combination of quota and convenience sampling was used, obtaining variation in gender, urban/rural residence, education, and age. The sample included 1,027 Blacks (528 females, 53 missing data on gender; $M_{\text {Age }}=33.08$ years, $S D=11.12$ ), 84 Coloureds and Indians (26 Afrikaans and 58 English speakers; 53 females; $M_{\text {Age }}=30.99$ years, $\left.S D=10.90\right)$, and 105 Whites (44 Afrikaans 61 English speakers; 67 females; $M_{\text {Age }}=32.21$ years, $S D=14.40$ ).

Instrument and procedure. Participants were asked to describe themselves and nine other persons they knew well: their best friend of the same sex, best friend of 
the opposite sex, a parent, their eldest child or sibling, a grandparent, a colleague or friend from another ethnic group, a person who is the total opposite of the participant, a teacher they liked (if schooled, otherwise a person from the village whom they liked), and a teacher they disliked (if schooled, otherwise a person from the village whom they disliked). In part of the interviews (580 Blacks, 49 Coloureds and Indians, and 47 Whites), no self-descriptions and descriptions of a person opposite to oneself were obtained; descriptions of a neighbor and a disliked person were obtained instead. The following four prompting questions were used: "Please describe the following people to me by telling me what kind of person he or she is/was;" "Can you describe typical aspects of this person?"; "Can you describe the behavior or habits that are characteristic of this person?"; and "How would you describe this person to someone who does not know him/her?". All participants were asked these questions and there was no limit to the number of descriptions provided per person. There were a total of 53,069 responses.

Data were collected by specially trained interviewers who were native speakers of the target language. The interviews were tape-recorded, transcribed, and translated into English by the interviewers. Language experts checked the accuracy of the translations and made corrections where necessary (Nel et al., 2012). The English translation was used in all analyses.

Coding. We based our coding scheme on work done with the TST (see, e.g., Rhee et al., 1995), adapting it to the present data where personality descriptions were specifically requested (e.g., we merged physical descriptions with other peripheral information). The coding scheme, with examples of each category, is presented in Table 1. Each response was coded for two independent features: category of personality description and contextualization. For the first feature, we distinguished 
between several categories of descriptions like traits and behaviors; for the second feature, we distinguished between absence and presence of several kinds of contextualizing information. All responses were coded by the first author. A second

Table 1

Coding Scheme for Categories of Personality Description and Contextualization

\begin{tabular}{ll}
\hline \multicolumn{1}{c}{ Category } & \\
\hline Description content & Examples \\
Trait & cheerful, helpful \\
Reified trait (virtue) & (has) sense of humor, respect \\
Behavior & makes jokes, cares \\
Preferences \& perceptions & likes, wants, willing to, believes/thinks, hopes, expects \\
Competency & knows, understands, is able to \\
Emotional state & (is, gets) afraid, irritated \\
Role & (like) a father to me \\
Role-fitting & (not) a good father \\
Relational state & always there, on good terms, close to me \\
Social identity & Christian, Zulu \\
Supernatural belief & believes in ancestors \\
Other-referring & people respect him, we do things together \\
Similarities \& opposites & we are similar, is like me \\
Peripheral to personality & divorced, tall, taxi driver, lives in Soweto \\
Others, uncodable & she is the reason I left school, friends are no good \\
Description contextualization & \\
Domain & helps with house chores \\
Temporal \& situational & when, if, sometimes, on certain occasions \\
General relational & with, to (people, others) \\
Specific relational & with, to (her husband) \\
Composite & respectful to people when they come to work \\
\hline a &
\end{tabular}

${ }^{\mathrm{a}}$ These two categories were used in order to account for all responses, but were not included in the analyses. The grand total number of responses before the exclusion of the responses in these categories was 62,837 .

rater was trained and a total interrater agreement (reflecting agreement on description categories and contextualization) of $85 \%$ was obtained for a random set of 200 responses.

Analysis. We analyzed the raw frequencies of all description categories using loglinear analysis. This approach is different from the established tradition in the studies on trait use, where proportions of trait responses are treated as a continuous variable. Our approach allows us to account for the properties of variables involving 
frequencies (Agresti, 2007), to accommodate more than one description categories in a unified analysis, and to avoid ipsatization issues when proportions are used. An example of ipsatization would be within-subject standardization of frequencies, so that all participants obtain the same standard number of responses; this is known to affect the results of multivariate analyses and has a debated validity (Hicks, 1970). We used loglinear analysis for all main analyses of the present study to investigate the associations between our categorical variables. In the following, we briefly introduce loglinear analysis (see also Agresti, 2007, and Tabachnick \& Fidell, 2007).

In loglinear analysis, combinations of independent variables form cells in a table, and the frequency in each cell is the dependent variable. The analysis tests a model with main effects (and lower order interactions) only against a model with (higher order) interactions. A significant goodness-of-fit statistic (likelihood ratio, LR, with a $\chi^{2}$ distribution) indicates a poor fit of the tested model, pointing to a significant effect of the (higher order) interactions. The specific sources of discrepancies can be identified using the standardized residuals: Expressed as $z$ scores, they indicate how much the observed frequency of a cell deviates from the one predicted by the tested model. Standardized residuals with absolute values above 2 are considered salient by common standards (Agresti, 2007). In the present study, we always test the model with the highest order interactions short of the saturated model.

\section{Results}

Trait use. To address cross-cultural differences in trait use, we first tested the fit of the model with main effects of category of personality description and ethnocultural group $^{1}$ as predictors. The model's fit was poor, $\operatorname{LR}(24, n=53,069)=$ $3,901.11, p<.001$, indicating a significant interaction. The proportions of each category of personality description per ethnocultural group are displayed in the upper 
panel of Table 2. The standardized residuals for the trait category suggested that traits were underrepresented in the Black group $(S R=-17.22)$ and overrepresented in the White $(S R=31.62)$ and the Coloured and Indian group $(S R=12.72)$. Given the similarity of the trait and reified trait categories, we merged these and constructed a binary trait variable (trait vs. non-trait) which we used in the subsequent analyses. On this binary variable, the proportion of traits out of all personality descriptions was .36 for Blacks, .54 for Coloureds and Indians, and .69 for Whites. ${ }^{2}$ We tested the model with main effects of the binary variable and ethnocultural group. This model also had a poor fit, $\operatorname{LR}(2, n=53,069)=2,754.36, p<.001$, and the standardized residuals were large and in the expected direction: $S R_{\mathrm{Black}}=-18.01, S R_{\mathrm{Col} / \mathrm{Ind}}=12.91$, and $S R_{\text {White }}=$ 33.40, indicating an underrepresentation of traits in the Black group and overrepresentation in the Coloured and Indian and especially in the White group. Hypothesis 1 was thus confirmed.

We further examined the use of all description categories. The findings suggested both similarities and differences between the three groups; the following points are particularly worth noting. First, the same categories - traits, behaviors, and preferences and perceptions - accounted for most responses in all three groups (over .86) as well as for the largest differences between groups (largest standardized residuals). Blacks tended to use relatively more behaviors (e.g., "he tells the truth") and preferences and perceptions (e.g., "he doesn't like lies," "he believes that truth will take you far in life"), and Whites more traits (e.g., "trustworthy"), with Coloureds and Indians displaying an intermediate pattern (see Table 2). Second and related, categories presumed important in the framework of individualism-collectivism, such as social roles and identities, had small relative frequencies in all three groups (around 
.01) so that interpretations of any differences on these were deemed to have little meaning. ${ }^{3}$ Finally, the position of the Coloured and Indian group deserves a closer

Table 2

Proportions (P), Standard Errors (SE), and Standardized Residuals (SR) of Categories of Personality

Description and Contextualization per Ethnocultural Group

\begin{tabular}{|c|c|c|c|c|c|c|c|c|c|}
\hline \multirow[b]{3}{*}{ Category } & \multicolumn{9}{|c|}{ Ethnocultural Group } \\
\hline & \multicolumn{3}{|c|}{ Black } & \multicolumn{3}{|c|}{ Coloured \& Indian } & \multicolumn{3}{|c|}{ White } \\
\hline & $P$ & $S E$ & $S R$ & $P$ & $S E$ & $S R$ & $P$ & $S E$ & $S R$ \\
\hline \multicolumn{10}{|l|}{ Description content } \\
\hline Trait & .34 & .005 & -17.22 & .50 & .020 & 12.72 & .64 & .022 & 31.62 \\
\hline Reified trait (virtue) & .02 & .001 & -5.33 & .03 & .004 & 2.38 & .05 & .003 & 11.17 \\
\hline Behavior & .29 & .004 & 7.13 & .25 & .014 & -1.74 & .16 & .013 & -16.23 \\
\hline Preferences \& perceptions & .26 & .005 & 18.19 & .08 & .006 & -21.08 & .07 & .006 & -26.58 \\
\hline Competency & .02 & .001 & -1.47 & .02 & .003 & 2.34 & .02 & .003 & 1.59 \\
\hline Emotional state & .01 & .001 & -0.49 & .02 & .002 & 2.81 & .01 & .002 & -1.28 \\
\hline Role & .01 & .000 & -0.45 & .01 & .002 & 2.47 & .00 & .001 & -1.07 \\
\hline Role-fitting & .01 & .000 & -1.13 & .01 & .001 & 2.36 & .01 & .001 & 0.71 \\
\hline Relational state & .01 & .001 & -0.68 & .01 & .002 & 3.82 & .01 & .001 & -1.71 \\
\hline Social identity & .01 & .001 & 3.20 & .00 & .001 & -4.17 & .00 & .001 & -4.28 \\
\hline Supernatural belief & .00 & .000 & 2.88 & .00 & .001 & -2.99 & .00 & .000 & -4.50 \\
\hline Other-referring & .03 & .002 & -1.90 & .05 & .005 & 7.35 & .03 & .004 & -1.79 \\
\hline Similarities \& opposites & .00 & .000 & -2.13 & .01 & .001 & 2.98 & .01 & .001 & 2.67 \\
\hline \multicolumn{10}{|l|}{ Description contextualization } \\
\hline Context-free & .66 & .004 & -8.02 & .76 & .011 & 5.75 & .85 & 013 & 14.87 \\
\hline Domain & .02 & .001 & -0.14 & .03 & .003 & 2.82 & .02 & .002 & -2.16 \\
\hline Temporal \& situational & .04 & .001 & 3.93 & .03 & .004 & -2.65 & .02 & .003 & -7.43 \\
\hline General relational & .10 & .002 & 7.01 & .05 & .005 & -8.83 & .05 & .005 & -9.61 \\
\hline Specific relational & .14 & .003 & 8.08 & .10 & .008 & -3.46 & .05 & .005 & -17.06 \\
\hline Composite & .04 & .002 & 5.56 & .02 & .003 & -4.49 & .01 & .002 & -9.87 \\
\hline
\end{tabular}

look. The proportion of behavior descriptions in this group (.25) was somewhat closer

to Blacks (.29) than to Whites (.16), whereas the proportion of preferences and

perceptions (.08) was closer to Whites (.07) than to Blacks (.26; see Table 2). This

intermediate pattern underscores their treatment as a separate group.

Contextualization. To examine contextualization, we tested a model with main effects of contextualization category (including context-free) and ethnocultural group. The model had a poor fit, $\operatorname{LR}(10, n=53,069)=1,288.47, p<.001$, indicating a significant interaction. The proportions of each contextualization category and the standardized residuals are presented in the lower panel of Table 2. In all three groups, 
the majority of descriptions were context-free (e.g., "helps a lot," "helpful"); yet, there were cross-cultural differences. Blacks employed the largest proportion of contextualization (.34) and Whites the smallest (.15), with Coloured and Indians in the middle (.24; the standardized residuals for the context-free category were -8.02 , 14.87, and 5.75, respectively). Hypothesis 2 was thus confirmed.

It could be argued that differences in contextualization are a by-product of differences in trait use: The greater use of contextualizing information could possibly be accounted for by the greater use of behavioral and other non-trait descriptions. This argument was tested using the same model with main effects of contextualization category and ethnocultural group, this time including only trait descriptions. The model had a poor fit, $\operatorname{LR}(10, n=22,277)=145.62, p<.001$, indicating a significant interaction. The standardized residuals had the same pattern as those for all descriptions, although seven of them (three each in the Black and in the Coloured and Indian group and one in the White group) were small and had an absolute value below 2. In sum, cross-cultural differences in contextualization were present even when considering only trait descriptions, indicating that cross-cultural differences in contextualization of personality descriptions cannot be accounted for by differences in trait use.

There were also cross-cultural differences with respect to the categories of contextualization. The two relational categories, general and specific, accounted for the largest proportions of qualified responses overall but were overrepresented in Blacks and underrepresented in the other two groups (see Table 2). It is interesting to note that these two categories showed somewhat different patterns across groups. Whereas the specific category (responses like "helpful to the poor") was used more often than the general category ("helpful to others") in the descriptions by Blacks 
(proportions of .14 and .10, respectively) and Coloureds and Indians (.10 and .05, respectively), they were used equally frequently by Whites (.05 for both categories; see Table 2 for the standardized residuals). These results suggest that Blacks as well as Coloureds and Indians have a stronger tendency than Whites to qualify personality descriptions by referring to specific, rather than general, relational contexts.

\section{Discussion}

We found support for the cultural psychology hypothesis regarding the use of trait descriptions across groups: Although all three groups use traits to describe persons, Blacks do this the least, and Whites the most, with Coloureds and Indians in the middle (Hypothesis 1). The difference is relative and traits were used at least to some extent in all groups; yet, the size of the difference is substantial.

Classical accounts of differences in trait use emphasize the importance of social groups and relations for self-concepts in collectivistic cultures. This importance of social orientation can be expressed in references to social roles and identities as well as in references to different self-concepts across different social roles (Cousins, 1989; Markus \& Kitayama, 1998; Triandis, 2001). In the present study, we found no support for social roles and identities as a strong alternative to traits. Personality descriptions in all three groups referred to social roles and group memberships only infrequently, providing more weight to traits, behaviors, and preferences and perceptions. So, responses like "I'm a Ndebele" and "he is a parent" were much less common than responses like "I respect everybody," "he likes to shout," and "he is generous." All these descriptions refer to individual characteristics; the Black participants, representing a collectivistic group, did not deemphasize individual characteristics in their descriptions. 
Regarding contextualization, we also found the expected overall differences in line with the cultural psychology perspective: Blacks had the largest proportion of contextualized responses and Whites the smallest, with Coloureds and Indians in the middle (Hypothesis 2). These differences were not entirely attributable to the use of trait or non-trait descriptions, underscoring the distinction between contextualization and trait use. Differences in contextualization were smaller than in trait use. The largest differences in contextualization were observed in the relational and composite categories: Blacks and, to a lesser extent, Coloureds and Indians qualified their personality descriptions more often in terms of relations (e.g., "he is respectful to the elderly") than Whites did (e.g., "respectful"). This leads back to the question of the meaning of social relations for personality concepts. It appears that the importance of social-relational aspects of personality in more collectivistic groups may not be expressed in different categories of personality description such as social roles and identities, but rather in their different semantic content (e.g., more references to traits and behaviors involving interpersonal relations and social functioning; cf. Valchev et al., in press) and the increased contextualization of personality descriptions in terms of relations.

In summary, in Part 1 we found similarities in the total set of categories used most often for personality description across the three groups, but also substantial differences between the groups in the relative use of these categories.

\section{Part 2: Interaction with Social Distance}

In Part 2, we aim to gain insight into the variation of the observed crosscultural differences in trait use and contextualization across levels of social distance between the participant and the target person. Do people use more (or fewer) traits to 
describe themselves, close others, or distant others, and does this tendency vary across ethnocultural groups? Depending on the theoretical framework, three different predictions are possible. First, construal-level theory (Liberman et al., 2007) suggests a general tendency to construe more abstract, trait-like representations for distant others and more concrete representations for the self and close others. Taking into account cross-cultural research on causal attribution (Choi et al., 1999), we would expect that this general tendency is most strongly present in the individualistic White group and less so, or not present at all, in the collectivistic Black group. Second, several theories view cross-cultural differences in trait use as stemming from different self-concepts (Markus \& Kitayama, 1998; Triandis, 2001). In light of evidence that close others are perceived in ways more similar to self-concepts than distant others (Pronin, 2008), we can hypothesize that cross-cultural differences are most pronounced in self-descriptions and in the opposite direction of that suggested by construal-level and attribution theories. So, contrary to the construal-level hypothesis, we would expect the highest proportions of traits for self-descriptions of Whites and lowest proportions for Blacks (with Coloureds and Indians in between), and less pronounced cross-cultural differences for more distant target persons. Third, if crosscultural differences reflect different concepts of the person in general (Shweder \& Bourne, 1984), we would expect approximately equally large differences for self- and other-descriptions. We test which of these competing hypotheses is supported by our data.

Different predictions can be formulated also regarding the contextualization of personality descriptions. On the one hand, from a cultural psychology perspective where traited and contextualized self-concepts and beliefs are seen as opposites (Heine \& Buchtel, 2009), contextualization and trait use are negatively related. On the 
other hand, it has also been argued that traitedness and contextualization are relatively independent (Kashima, 2001; Kashima et al., 2006), which would imply that the interaction of contextualization with social distance can be absent or follow different patterns from that of trait use. We assess the merits of both perspectives by examining the role of social distance separately for trait use and contextualization.

\section{Method}

We grouped the described target persons in four groups varying in social distance: self, family (parent, child or sibling, and grandparent), close others (best friend of both sexes and neighbor), and distant others (colleague, least, and most liked teacher).

\section{Results}

We tested a model with main effects and two-way associations of the binary trait variable, ethnocultural group, and social distance. The model had a poor fit, $\operatorname{LR}(6, n=46,658)=204.53, p<.001$, indicating a significant higher order interaction. The proportions of traits per ethnocultural group and target person are presented in Table 3. The use of traits differed depending on social distance from the target person, and this in turn differed across cultural groups. Trait use decreased with increasing social distance in the White and the Coloured and Indian group, whereas in the Black group it was the lowest for self-descriptions and the highest for the middle categories, with overall smaller amplitudes than in the former two groups. The differences in trait use across the three groups were the largest for self-descriptions: Blacks' selfdescriptions employed traits at a proportion of .28, those of Whites .88, and Coloureds and Indians were closer to Whites with .68 trait use (for the standardized residuals, see Table 3). The group differences for the other target persons were smaller, although still substantial. In summary, groups differed most in their self-descriptions, 
providing support for the self-concept hypothesis over the person-concept and the construal-level hypotheses. The use of traits was affected by social distance more strongly in Whites and in Coloureds and Indians than in Blacks.

Table 3

Proportions (P), Standard Errors (SE), and Standardized Residuals (SR) of Traits per Target Person and Ethnocultural Group

\begin{tabular}{|c|c|c|c|c|c|c|c|c|c|}
\hline \multirow[b]{3}{*}{ Target Person } & \multicolumn{9}{|c|}{ Ethnocultural Group } \\
\hline & \multicolumn{3}{|c|}{ Black } & \multicolumn{3}{|c|}{ Coloured \& Indian } & \multicolumn{3}{|c|}{ White } \\
\hline & $P$ & $S E$ & $S R$ & $P$ & $S E$ & $S R$ & $P$ & $S E$ & $S R$ \\
\hline Self & .28 & .012 & -5.08 & .68 & .043 & 4.07 & .88 & .024 & 5.22 \\
\hline Family & .38 & .006 & -0.46 & .56 & .021 & 0.62 & .70 & .022 & 0.36 \\
\hline Close others & .38 & .007 & 1.24 & .52 & .026 & -1.43 & .67 & .026 & -1.13 \\
\hline Distant others & .33 & .006 & 1.66 & .46 & .024 & -1.34 & .60 & .025 & -1.94 \\
\hline
\end{tabular}

For the analysis of contextualization, we tested a model with main effects and two-way associations of a binary contextualization variable (absent or present), ethnocultural group, and social distance. The model had a poor fit, $\operatorname{LR}(6, n=46,658)$ $=44.10, p<.001$, indicating a significant higher order interaction. The proportions of contextualized responses per ethnocultural group and target person are presented in Table 4. The results were similar to the analysis of trait use (with an opposite sign, cf. Table 3), with overrepresentation of contextualized self-descriptions in Blacks and underrepresentation in the other two groups. However, compared to trait use, the effects were relatively small and there was a common tendency for all three groups to contextualize self-descriptions least and distant other-descriptions most. In summary, groups differed in their contextualization of personality descriptions across social distance similarly but less markedly than in trait use, providing more support for views of trait use and contextualization as only partially related. 
Table 4

Proportions (P), Standard Errors (SE), and Standardized Residuals (SR) of Contextualized Responses per Target Person and Ethnocultural Group

\begin{tabular}{|c|c|c|c|c|c|c|c|c|c|}
\hline \multirow[b]{3}{*}{ Target Person } & \multicolumn{9}{|c|}{ Ethnocultural Group } \\
\hline & \multicolumn{3}{|c|}{ Black } & \multicolumn{3}{|c|}{ Coloured \& Indian } & \multicolumn{3}{|c|}{ White } \\
\hline & $P$ & $S E$ & $S R$ & $P$ & $S E$ & $S R$ & $P$ & $S E$ & $S R$ \\
\hline Self & .30 & .010 & 2.09 & .12 & .018 & -3.03 & .06 & .011 & -3.83 \\
\hline Family & .33 & .004 & 0.14 & .23 & .010 & -0.27 & .15 & .008 & -0.24 \\
\hline Close others & .30 & .004 & -0.40 & .22 & .011 & 0.62 & .14 & .008 & 0.78 \\
\hline Distant others & .41 & .005 & -0.59 & .32 & .013 & 0.96 & .22 & .011 & 1.08 \\
\hline
\end{tabular}

\section{Discussion}

We found that distance from the described person affects the use of traits and contextualization for personality descriptions differently across cultural groups. The effects were larger for trait use than for contextualization, highlighting the distinction between the two variables (Kashima, 2001). The largest group differences were concentrated in self-descriptions, where the most traits were used by Whites as well as Coloureds and Indians, and the fewest by Blacks. This finding is in line with expectations defined in terms of differences in self-concepts (Markus \& Kitayama, 1998; Triandis, 2001) rather than more general person concepts (Shweder \& Bourne, 1984) or construal level (Liberman et al., 2007) and attribution tendencies (Choi et al., 1999). It is somewhat counterintuitive, however, that the descriptions of Whites (and, similarly, Coloureds and Indians) were the most affected by social distance. This seems to imply that people in the more individualistic groups are more sensitive to social context, contrary to fundamental premises and findings of the individualismcollectivism framework (Markus \& Kitayama, 1998; Triandis, 2001; Triandis \& Suh, 2002). The interaction between social distance and culture was large for trait use, and 
none of the approaches considered may be able to fully account for the differences. Therefore, we examine two additional interpretations.

One interpretation is that the differences in self- and other-descriptions reflect differences in content: Whites (and, to a lesser extent, Coloureds and Indians) might have more elaborated self-concepts in terms of personality dispositions and behavior tendencies than Blacks. If that were the case, we could expect that the three groups differ in a similar way in the diversity of personality concepts they use to describe different target persons. To test this, we made an index for the proportion out of nine personality clusters that participants used to describe each target person (see the method section of Part 3 for a description of the clusters). The proportions are displayed in Table 5. The self-descriptions in all three groups employed the lowest proportion of clusters; however, if one corrects for the fact that the other-descriptions cover on average three persons per level of social distance, all other-descriptions could be considered to include smaller proportions of clusters, across all groups. So, the differences in proportions of clusters used for self- and other-description did not follow the same pattern across ethnocultural groups as the differences in the use of traits for self- and other-descriptions (cf. Tables 3 and 5). In conclusion, the interpretation that the group differences in the use of traits reflect group differences in

Table 5

Mean Proportions of Clusters Used for Personality Description per Target Person and Ethnocultural Group (SD in parentheses)

\begin{tabular}{lccc}
\hline \multirow{2}{*}{ Target Person } & \multicolumn{3}{c}{ Ethnocultural Group } \\
\cline { 2 - 4 } Self & $.34(.17)$ & Coloured \& Indian & White \\
Family & $.55(.16)$ & $.45(.18)$ & $.43(.18)$ \\
Close others & $.48(.18)$ & $.67(.19)$ & $.65(.16)$ \\
Distant others & $.49(.19)$ & $.63(.17)$ & $.60(.18)$ \\
\hline
\end{tabular}


level of elaboration of personality (self- and other-) concepts does not seem to be supported.

An alternative interpretation is that individuals in the three ethnocultural groups express their knowledge of persons differently. The availability of abstract terms in the repertoire of the speaker is crucial to facilitate the expression of better person knowledge in more abstract terms. This availability, in turn, could be associated with education and exposure to abstract terms in general, or abstract personality terms in particular. Unfortunately, we did not have data on education level in all groups, which precluded its inclusion as a covariate in our main analyses. Nonetheless, we used the available data to test for the role of education. We had data on education for 393 participants, all in the Black group, from four languages (Northern Sotho, Ndebele, Xhosa, and Tsonga). There were 12 participants with no education, 124 with high school, 175 with further professional education, and 82 with high education. We conducted a loglinear analysis testing the model with main effects of trait use and education. The model had a poor fit, $\operatorname{LR}(3, n=16,144)=96.54, p<$ .001 , indicating a significant interaction. Although the three lower education cells did not display monotonously increasing proportions of traits $(.35, .30$, and .31 , with $S R \mathrm{~s}$ $=0.46,-3.63$, and -2.45 , respectively), the high-education cell had the highest proportion of traits, as expected $(.40, S R=6.95)$. This analysis suggested that having high education is linked with greater use of traits, in line with the interpretation that the more traited personality descriptions reflect a preferred mode of expression, facilitated by education. Similar effects of education level have been reported by Ma and Schoeneman (1997) for Kenyan participants. It should be noted that the proportion of traits of the highly educated Black participants in the present study (.40) 
was closer to the proportions of Black participants with lower education (.30 to .35$)$ than to those of Coloureds and Indians (.54) and Whites (.69). So, even though individual education had an effect on trait use, it was not a strong determinant. Future studies should address the effects of education across ethnocultural groups.

In summary, in Part 2 we found that distance from the target person plays a role in cross-cultural differences in trait use and contextualization in a way that goes beyond predictions derived from a single theoretical framework within either cultural or trait psychology.

\section{Part 3: Interaction with Personality Domains}

The third study part examines the use of traits and contextualization at the level of personality domains. First, we examine the relationship between trait use and the content of personality descriptions (partly on all data and partly in four languages representative of the major linguistic groups, viz., English, Tsonga, Tswana, and Xhosa). Based on previous research on the content of self-descriptions in the individualism-collectivism framework (Del Prado et al., 2007; Sedikides et al., 2005), we expect people in more collectivistic groups to use more communal and fewer agentic traits than people in more individualistic groups. Integrating this perspective with the psycholexical hypothesis (Saucier \& Goldberg, 2001), we expect relatively greater use of traits for the more salient characteristics in each group, that is, for communal characteristics in the more collectivistic groups, and agentic characteristics in the more individualistic groups. We test the following hypotheses:

Hypothesis 3: Blacks use the smallest proportion of agentic traits and Whites the largest, with Indians in between; the reverse is true for communal traits. 
Hypothesis 4: Blacks use relatively more traits (vs. non-traits) for the communal category and Whites relatively fewer, with Indians in between; the reversed pattern is expected for the agentic category.

The relative frequency of both agentic and communal elements could vary across personality dimensions (DeYoung, Quilty, \& Peterson, 2007; Roccas, Sagiv, Schwartz, \& Knafo, 2002). However, there is no established theoretical framework that could specify the relation between trait use and specific personality concepts like the Big Five or the nine personality clusters identified in South Africa (Nel et al., 2012). Therefore, we refrain from specifying any hypotheses when we examine differences in the use of traits for different personality clusters across ethnocultural groups.

We then proceed to examine cross-cultural differences in the contextualization of different personality domains. We address two questions: First, which personality domains are more contextualized, and do these domains differ across cultures? And second, do these differences mirror the differences in trait use? The answer to the first question will shed light on the perceived situatedness of personality functioning across domains, and the answer to the second question will provide evidence on the relation between trait use and contextualization.

\section{Method}

For the agentic-communal distinction, a student coded responses (traits as well as non-traits) as agentic (e.g., "determined," "strong-willed," "I like working with my hands"), communal (e.g., "kind," "loving," "he understands my problems"), or neutral (e.g., "quiet," "she used to steal"). Interrater agreement of $80 \%$ was achieved by two raters on 100 random responses (the first author was the second rater). We analyzed only the descriptions coded as either agentic or communal. Given 
the substantial amount of time and effort required for the additional coding, we restricted this analysis to four languages, representative of the major groups within South Africa's 11 official languages: English (of the Germanic group), Tswana (of the Sotho-Tswana group), Xhosa (of the Nguni group), and Tsonga (which, together with Venda, does not belong to a specific subgroup). The sample consisted of 360 Blacks, 58 Indians, and 61 Whites; no Coloureds were included in this analysis.

The data on the personality clusters came from an independent study on all 11 languages in which we had categorized the original responses in iterative steps into 188 facets, 37 subclusters, and nine broad clusters of personality (Nel et al., 2012). ${ }^{5}$ The nine clusters are: Conscientiousness (with descriptions like "dedicated to his work”), Emotional Stability (e.g., “cries a lot”), Extraversion (e.g., "I love communicating with people"), Facilitating (e.g., "gives advice about life"), Integrity

(e.g., "honest with her parents"), Intellect (e.g., "a person that doesn't use his common sense”), Openness (e.g., "adventurous"), Relationship Harmony (e.g., "likes to quarrel"), and Soft-Heartedness (e.g., "she is a friendly person"). The clusters have a broad correspondence to the Big Five factors, with Openness split into Intellect and Openness, and the Agreeableness domain being represented in Soft-Heartedness, Relationship Harmony, Facilitating, and Integrity (Nel et al., 2012).

\section{Results}

Trait use across personality domains. To test Hypothesis 3, we tested a model with main effects of the binary agentic-communal variable (including only trait responses) and ethnocultural group. The model had a poor fit, $\operatorname{LR}(2, n=7,440)=$ $102.92, p<.001$, indicating a significant interaction. The standardized residuals showed the expected direction, indicating an underrepresentation of agentic traits in the Black group $(.37, S E=.01 ; S R=-5.16)$ and an overrepresentation in the White 
$(.50, S E=.02 ; S R=4.59)$ and the Indian group $(.48, S E=.02 ; S R=3.40)$, and the reverse pattern for communal traits $\left(S R_{\text {Black }}=4.14, S R_{\text {White }}=-4.55\right.$, and $S R_{\text {Indian }}=$ -1.80). Hypothesis 3 was thus confirmed.

To test Hypothesis 4, we examined a model with main effects and two-way associations of the binary agentic-communal variable (including both traits and nontraits), the binary variable for trait use, and ethnocultural group. The model had a poor fit, $\operatorname{LR}(2, n=17,988)=65.80, p<.001$, indicating a significant higher order interaction. The proportions and standardized residuals are displayed in the upper panel of Table 6 . The proportions of traits were overall higher for the agentic descriptions. After taking into account the main effects and two-way associations, traits were underrepresented in the agentic descriptions of Blacks and overrepresented in those of Indians and Whites, and the reverse was true for communal descriptions (see Table 6). In summary, Blacks not only tended to use communal traits more often, but also tended to express communal characteristics more often with traits than would be predicted by the main effects of trait use and agentic-communal preferences, confirming Hypothesis 4.

The next analysis addressed the patterning of responses across personality clusters. We tested a model with main effects and two-way associations of the binary variable for trait use, personality cluster, and ethnocultural group. The model had a poor fit, $\operatorname{LR}(16, n=49,190)=379.61, p<.001$, indicating a significant higher order interaction. The proportions of traits per personality cluster and ethnocultural group and the standardized residuals of the model are displayed in the lower panel of Table 6. The personality cluster that stood out was Openness: Traits were heavily underrepresented for this cluster in Blacks $(S R=-8.13)$ while they were overrepresented in Coloureds and Indians $(S R=9.86)$ and Whites $(S R=7.87)$. A 
much smaller overrepresentation of traits was found for Emotional Stability in Blacks and an underrepresentation in the other two groups (see Table 6).

Table 6

Proportions (P), Standard Errors (SE), and Standardized Residuals (SR) of Traits per Personality

Domain and Ethnocultural Group

\begin{tabular}{|c|c|c|c|c|c|c|c|c|c|}
\hline \multirow[b]{3}{*}{ Personality Domain } & \multicolumn{9}{|c|}{ Ethnocultural Group } \\
\hline & \multicolumn{3}{|c|}{ Black } & \multicolumn{3}{|c|}{ Coloured \& Indian } & \multicolumn{3}{|c|}{ White } \\
\hline & $P$ & $S E$ & $S R$ & $P$ & $S E$ & $S R$ & $P$ & $S E$ & $S R$ \\
\hline \multicolumn{10}{|l|}{ Agentic vs. communal } \\
\hline Agentic & .38 & .012 & -2.93 & .66 & .021 & 2.54 & .72 & .021 & 1.79 \\
\hline Communal & .32 & .009 & 2.39 & .45 & .025 & -2.25 & .54 & .027 & -1.67 \\
\hline \multicolumn{10}{|l|}{ Personality cluster } \\
\hline Conscientiousness & .55 & .011 & 0.47 & .67 & .030 & -0.58 & .79 & .026 & -0.43 \\
\hline Emotional Stability & .56 & .014 & 2.01 & .59 & .033 & -2.24 & .75 & .024 & -1.26 \\
\hline Extraversion & .38 & .008 & -0.21 & .57 & .024 & 1.04 & .67 & .024 & -0.48 \\
\hline Facilitating & .11 & .008 & -0.19 & .23 & .031 & 0.85 & .29 & .045 & -0.50 \\
\hline Integrity & .43 & .011 & -1.69 & .65 & .035 & 0.98 & .82 & .027 & 2.23 \\
\hline Intellect & .34 & .014 & 0.20 & .54 & .037 & 1.06 & .59 & .033 & -1.13 \\
\hline Openness & .07 & .007 & -8.13 & .53 & .037 & 9.86 & .63 & .043 & 7.87 \\
\hline Relationship Harmony & .37 & .009 & 0.80 & .49 & .036 & -0.88 & .63 & .037 & -0.98 \\
\hline Soft-Heartedness & .42 & .007 & 1.41 & .54 & .025 & -2.37 & .70 & .026 & -0.89 \\
\hline
\end{tabular}

Note. The data for the agentic-communal categories were derived in four languages: English, Tsonga,

Tswana, and Xhosa. The Coloured group is not represented in this analysis.

Contextualization across personality domains. To examine the use of contextualization across personality domains, we ran the same two analyses as with trait use, this time with the binary variable of contextualization. We first tested a model with main effects and two-way associations of the agentic-communal variable, the contextualization variable, and ethnocultural group. The model had a poor fit, $\operatorname{LR}(2, n=17,988)=75.13, p<.001$, indicating a significant higher order interaction. The proportions and standardized residuals are presented in the upper panel of Table 7. The large interaction effects were concentrated in the agentic category, where Blacks used fewer context references $(S R=-4.04)$, while both Indians $(S R=6.21)$ and Whites $(S R=3.37)$ used more than predicted by the main-effects model. For the communal category, the effects were in the opposite direction although smaller. 
Table 7

Proportions (P), Standard Errors (SE), and Standardized Residuals (SR) of Contextualized

Descriptions per Personality Domain and Ethnocultural Group

\begin{tabular}{|c|c|c|c|c|c|c|c|c|c|}
\hline \multirow[b]{3}{*}{ Personality Domain } & \multicolumn{9}{|c|}{ Ethnocultural Group } \\
\hline & \multicolumn{3}{|c|}{ Black } & \multicolumn{3}{|c|}{ Coloured \& Indian } & \multicolumn{3}{|c|}{ White } \\
\hline & $P$ & $S E$ & $S R$ & $P$ & $S E$ & $S R$ & $P$ & $S E$ & $S R$ \\
\hline \multicolumn{10}{|l|}{ Agentic vs. communal } \\
\hline Agentic & .07 & .005 & -4.04 & .11 & .013 & 6.21 & .07 & .009 & 3.37 \\
\hline Communal & .50 & .009 & 1.23 & .36 & .018 & -1.97 & .31 & .018 & -1.10 \\
\hline \multicolumn{10}{|l|}{ Personality cluster } \\
\hline Conscientiousness & .20 & .009 & 0.16 & .14 & .019 & 0.37 & .07 & .013 & -0.95 \\
\hline Emotional Stability & .21 & .011 & -1.29 & .19 & .025 & 2.15 & .11 & .016 & 1.42 \\
\hline Extraversion & .29 & .007 & 0.59 & .17 & .015 & -1.37 & .12 & .013 & -0.38 \\
\hline Facilitating & .66 & .013 & 0.47 & .48 & .037 & -1.05 & .35 & .045 & -0.80 \\
\hline Integrity & .27 & .009 & 0.45 & .16 & .028 & -0.71 & .10 & .017 & -0.86 \\
\hline Intellect & .21 & .011 & -2.07 & .20 & .025 & 2.12 & .16 & .022 & 3.97 \\
\hline Openness & .11 & .007 & -2.06 & .16 & .024 & 4.49 & .11 & .018 & 4.81 \\
\hline Relationship Harmony & .36 & .009 & -0.18 & .23 & .023 & -1.02 & .20 & .024 & 1.98 \\
\hline Soft-Heartedness & .46 & .006 & 0.68 & .33 & .017 & -0.30 & .21 & .018 & -2.16 \\
\hline
\end{tabular}

Note. The data for the agentic-communal categories were derived in four languages: English, Tsonga,

Tswana, and Xhosa. The Coloured group is not represented in this analysis.

Finally, we tested a model with main effects and two-way associations of the binary contextualization variable, personality cluster, and ethnocultural group. The model had a poor fit, $\operatorname{LR}(16, n=49,190)=98.48, p<.001$, indicating a significant higher order interaction. The proportions and standardized residuals are presented in the lower panel of Table 7. Across groups, the clusters that have to do more with the quality of social functioning (Facilitating, Relationship Harmony, and SoftHeartedness) were more contextualized than those with a more person-centered focus (Conscientiousness, Intellect, and Openness). The cross-cultural differences were most systematic for Intellect and Openness, where contextual information was underrepresented in Blacks and overrepresented in the other two groups. A similar pattern was observed for Emotional Stability with smaller effects (see Table 7). 


\section{Discussion}

We sought to expand the mainstream literature on trait use by addressing the effects of culture on the use of traits and contextualizing information across personality domains. We started with an examination of agency-communion, which are broad constructs that have been suggested to capture substantial cross-cultural differences in personality descriptions (Del Prado et al., 2007; Sedikides et al., 2005). Consistent with literature, we found that Blacks used more communal traits than Whites (Hypothesis 3); Indians were closer to Whites in this analysis.

Moreover, in confirmation of Hypothesis 4, we found that Blacks, as compared to the other two groups, used a relatively large proportion of traits in communal descriptions. A similar observation was made in the analysis of clusters, where traits in the two clusters presumably most relevant to the quality of social functioning, Relationship Harmony and Soft-Heartedness, were slightly overrepresented in Blacks and underrepresented in the other two groups. The relatively greater use of traits for communal descriptions by members of the more collectivistic groups is in line with the psycholexical interpretation of trait terms as expressing the personality concepts deemed most important among speakers of a given language (Saucier \& Goldberg, 2001).

On the level of personality clusters, we found few systematic differences in trait use. The most obviously affected cluster was Openness, where Blacks used fewer traits than predicted by the main effects and two-way associations of trait use, cluster, and ethnocultural group. This finding comes against the backdrop of well documented problems with the replicability of the Openness factor, especially in collectivistic cultures (e.g., McCrae \& Allik, 2002). Perhaps these problems are to some extent attributable to a lack of abstract terms for Openness in some cultures, rather than lack 
of the concept itself. For instance, Openness replicated better in Africa in the study of Schmitt, Allik, McCrae, Benet-Martinez, and colleagues (2007), which utilized whole phrases as opposed to previous studies that had used single abstract terms. Indeed, an inspection of the semantic content of the Openness cluster in our data suggested that about one third of its facets consisted of single terms which were mostly represented in the two Germanic languages: Adventurous, Dreamer, Individualistic, Investigating (later merged with Inquisitive), and Prim and Proper. This underscores the interpretation that single trait terms referring to Openness are more readily available and used in individualistic than in collectivistic cultures.

Furthermore, we were interested in the question, which personality concepts are perceived to be most in need of situational specification across cultures (De Raad et al., 2008). Communal characteristics and the clusters that have to do more with the quality of interpersonal relations (Facilitating, Relationship Harmony, and SoftHeartedness) were more contextualized than those with a more person-centered focus (Conscientiousness, Intellect, and Openness). ${ }^{6}$ This distinction appeared most clearly in the Black group, although the interactions of ethnocultural group with contextualization across personality domain were the largest for the agentic descriptions, Intellect, and Openness.

We also examined to what extent cross-cultural differences in contextualization across personality domains mirror differences in trait use. If this were the case, we would expect opposite patterns for the corresponding rows of Tables 6 and 7. However, what we found was that the patterns were in the same direction for the agentic-communal dimension and Openness, and in the opposite direction, although less pronounced, for Emotional Stability. It appears that crosscultural differences in the use of abstract terms to describe particular personality 
concepts do not necessarily imply corresponding differences in the use of contextual information.

Finally, it is interesting to note that the clusters that displayed the largest interactions of ethnocultural group with both trait use and contextualization (Openness, Intellect, and Emotional Stability) are among the smaller and more contested factors in psycholexical studies (De Raad et al., 2010; Saucier \& Goldberg, 2001). Our study suggests that differences in trait use and contextualization may indeed complicate the observation of these clusters in psycholexical studies. It seems fair to conclude that when specific personality clusters are concerned, large crosscultural differences can be expected mostly in the more peripheral personality concepts.

In summary, in Part 3 we found significant interactions of culture with the use of traits and contextual information, on the one hand, and personality domains, on the other. Our findings suggest that (a) traits are used most for the most salient concepts in all cultures; (b) trait use and contextualization do not co-vary completely; and (c) the largest interactions with culture occur in the smaller personality clusters.

\section{General Discussion}

We examined cross-cultural differences in characteristics of personality description between three ethnocultural groups in South Africa: Blacks, Coloureds and Indians, and Whites. We found support for all hypotheses formulated in accordance with the cultural psychology perspective and the individualismcollectivism framework. The three groups revealed the expected differences with respect to use of traits (Hypothesis 1) and contextualizing information (Hypothesis 2), use of agentic versus communal traits (Hypothesis 3), and use of traits for agentic versus communal descriptions (Hypothesis 4). The responses of Blacks were 
consistent with expectations for collectivistic groups (where fewer traits and more contextualization are expected) and those of Whites for individualistic groups (where more traits and less contextualization are expected), with Coloureds and Indians generally displaying intermediate patterns, closer to Blacks in some analyses and to Whites in others.

These results have several implications for the trait and cultural psychology perspectives on trait use. First, the differences posited in the individualismcollectivism framework extend beyond East-West comparisons and apply also to the African context. This restricts interpretations linking differences in trait use specifically to Asian cultural characteristics such as dialectical thought (Church, 2009; Del Prado et al., 2007) because Asian dialecticism can be assumed to be of limited relevance in the South African context. Although the individuals in many nonWestern cultures may share features that make them different from the populations typically studied in mainstream psychology (for a recent overview, see Henrich, Heine, \& Norenzayan, 2010), and some of these features may affect personality conceptions in a similar way across cultures, these features could hardly be subsumed under the single concept of Asian dialecticism, which has a specific cultural-historical and philosophical background (Nisbett et al., 2001; Spencer-Rodgers, Williams, \& Peng, 2010). Second, trait use differences may be more fruitfully thought of as lying on a continuum rather than in dichotomous terms. The intermediate characteristics of personality descriptions made by Coloureds and Indians illustrate this point. Third, although our findings are supportive of the cultural psychology perspective, they also support the trait perspective insofar as traits were used in all three groups. Nonetheless, the substantial group differences should be emphasized: The overall proportion of traits was .36 in Blacks' descriptions and .69 in Whites; for self- 
descriptions, the difference was even more remarkable with .28 traits in Blacks and .88 in Whites. In practical terms, these findings strongly suggest that items with concrete behaviors should be used in the development of personality assessment tools for comparisons involving more collectivistic and more individualistic groups (cf. Schmitt et al., 2007, on Openness in Africa).

On the other hand, our study suggests that there are important questions which cannot be addressed from either the trait or cultural psychology perspective. This becomes evident when one considers the preferred categories of personality description beyond traits, the contextualization of descriptions, the role of social distance from the described person, and the substantiation of differences across personality domains. We found that Blacks made more descriptions using behaviors, preferences, and relational contextualization than the other groups (however, all three groups made few references to social roles and identities); they used the fewest traits for self-descriptions but had overall small differences across social distance; they used relatively few traits and little contextualizing information for agentic descriptions and Openness. Whites had the opposite pattern, and Coloureds and Indians had an intermediate pattern. These complex patterns could not have been predicted from the trait or cultural psychology perspective alone. Furthermore, the present study suggests that cross-cultural personality research needs to go beyond classical cultural psychology interpretations of trait use and contextualization as opposites. Trait use and contextualization should be disentangled because their association is not fixed: They are negatively related in some instances and positively in others. The specific characteristics of context should be taken into account; what matters most may often be not just any context or situation, but specifically relational context. Finally, the formulation of our Hypotheses 3 and 4, discussed above as supportive of the cultural 
psychology perspective, required additional theoretical considerations about agentic and communal descriptions (Del Prado et al., 2007; Sedikides et al., 2005) and the psycholexical hypothesis (Saucier \& Goldberg, 2001). This integration of different perspectives is in line with efforts to bring the study of trait use beyond the juxtaposition of the trait and cultural psychology perspectives (Church, 2000, 2009). In summary, we found that the individualism-collectivism framework adequately predicts cross-cultural differences between ethnocultural groups in South Africa, whereby the groups can be placed on a continuum from more collectivistic (Blacks) to intermediate (Coloureds and Indians) to more individualistic (Whites). At the same time, we found that the implications of this framework need to be modified and expanded at several points. First, when personality descriptions are specifically requested, cross-cultural differences are concentrated in the relative use of traits, behaviors, preferences and perceptions, and relational contextual information, but not in other social-relational categories such as social roles and identities. Despite the failure of some previous studies to find the expected cross-cultural differences in references to social roles and identities (Kanagawa et al., 2001; Rhee et al., 1995), much literature in the individualism-collectivism tradition has emphasized the importance of these categories (Cousins, 1989; Ma \& Schoeneman, 1997; Markus \& Kitayama, 1998; Triandis, 2001). The prevailing use of disposition-relevant descriptions across cultural groups found in the present study is in line with the individual-self-primacy hypothesis (Gaertner, Sedikides, Vevea, \& Iuzzini, 2002) but has broader ramifications involving both self-concepts and concepts of others. The cross-cultural differences appear to be differences in salience and manifestation, rather than in the fundamental substance of personality conceptions (cf. Valchev et al., in press). Second, our data suggest that people in more individualistic cultures 
adapt their personality descriptions more to the target of their descriptions, employing more traits for those they know best (themselves and close others). The use of traits for personality descriptions of different target persons appears to constitute a remarkable exception to the general rule of increased sensitivity to social context in collectivistic cultures (Kanagawa et al., 2001; Markus \& Kitayama, 1998). Finally, the interaction of trait use with personality domain should be taken into account. Both on the level of broad concepts like agency and communion and narrower concepts like specific personality clusters, more traits tend to be used for more salient characteristics. The cross-cultural differences in trait use and contextualization tend to be most pronounced for more peripheral personality concepts.

Recent research on traits and context often turns to topics beyond trait use in personality description, such as the direct measurement of implicit trait beliefs (Church et al., 2003), cross-role (Church, Anderson-Harumi, et al., 2008) and crosssituational behavior consistency (Church, Katigbak, et al., 2008; see also Church, 2009). Our study demonstrates that much is to be gained from a better understanding of the basic characteristics of personality descriptions across cultures. The research field of implicit trait beliefs and personality conceptions will be enriched if future studies pay serious attention to understudied populations, to mechanisms affecting trait use such as language, education, and social distance, and to the interplay of trait use and contextualization with the semantic content of personality descriptions.

\section{References}

Agresti, A. (2007). An introduction to categorical data analysis (2nd ed.). Hoboken, NJ: Wiley-Interscience.

Allik, J., \& McCrae, R. R. (2004). Toward a geography of personality traits: Patterns of profiles across 36 cultures. Journal of Cross-Cultural Psychology, 35, 13-28. 
doi:10.1177/0022022103260382

Allport, G. W., \& Odbert, H. S. (1936). Trait-names: A psycho-lexical study. Psychological Monographs, 47, No. 211.

Bakan, D. (1966). The duality of human existence: Isolation and communion in Western man. Boston, MA: Beacon Press.

Benet-Martínez, V., \& Oishi, S. (2008). Culture and personality. In O. P. John, R. W. Robins, \& L. A. Pervin (Eds.), Handbook of personality: Theory and research (pp. 542-567). New York, NY: Guilford Press.

Choi, I., Nisbett, R. E., \& Norenzayan, A. (1999). Causal attribution across cultures: Variation and universality. Psychological Bulletin, 125, 47-63. doi:10.1037/00332909.125.1.47

Church, A. T. (2000). Culture and personality: Toward an integrated cultural trait psychology. Journal of Personality, 68, 651-703. doi:10.1111/1467-6494.00112

Church, A. T. (2009). Prospects for an integrated trait and cultural psychology. European Journal of Personality, 23, 153-182. doi:10.1002/per.700

Church, A. T. (2010). Current perspectives in the study of personality across cultures. Perspectives on Psychological Science, 5, 441-449. doi:10.1177/1745691610375559

Church, A. T., Anderson-Harumi, C. A., Del Prado, A. M., Curtis, G. J., Tanaka-Matsumi, J., Valdez Medina, J. L., ... White, F. A. (2008). Culture, cross-role consistency, and adjustment: Testing trait and cultural psychology perspectives. Journal of Personality and Social Psychology, 95, 739-755. doi:10.1037/0022-3514.95.3.739

Church, A. T., Katigbak, M. S., \& Del Prado, A. M. (2010). Cultural similarities and differences in perceived affordances of situations for Big Five behaviors. Journal of Research in Personality, 44, 78-90. doi:10.1016/j.jrp.2009.11.003

Church, A. T., Katigbak, M. S., Reyes, J. A., Salanga, M. G., Miramontes, L. G., \& Adams, N. B. (2008). Prediction and cross-situational consistency of daily behavior across cultures: Testing trait and cultural psychology perspectives. Journal of Research in Personality, 42, 1199-1215. doi:10.1016/j.jrp.2008.03.007 
Church, A. T., Ortiz, F. A., Katigbak, M. S., Avdeyeva, T. V., Emerson, A. M., Vargas Flores, J. J., \& Ibáñez Reyes, J. (2003). Measuring individual and cultural differences in implicit trait theories. Journal of Personality and Social Psychology, 85, 332-347. doi:10.1037/0022-3514.85.2.332

Cousins, S. D. (1989). Culture and self-perception in Japan and the United States. Journal of Personality and Social Psychology, 56, 124-131. doi:10.1037/0022-3514.56.1.124

De Raad, B. (1999). Interpersonal lexicon: Structural evidence from two independently constructed verb-based taxonomies. European Journal of Psychological Assessment, 15, 181-195. doi:10.1027//1015-5759.15.3.181

De Raad, B., Barelds, D. P. H., Levert, E., Ostendorf, F., Mlačić, B., Di Blas, L., ... Katigbak, M. S. (2010). Only three factors of personality description are fully replicable across languages: A comparison of 14 trait taxonomies. Journal of Personality and Social Psychology, 98, 160-173. doi:10.1037/a0017184

De Raad, B., Sullot, E., \& Barelds, D. P. H. (2008). Which of the Big Five factors are in need of situational specification? European Journal of Personality, 22, 269-289. doi:10.1002/per.668

Del Prado, A. M., Church, A. T., Katigbak, M. S., Miramontes, L. G., Whitty, M. T., Curtis, G. J., ... Reyes, J. A. S. (2007). Culture, method, and the content of self-concepts: Testing trait, individual-self-primacy, and cultural psychology perspectives. Journal of Research in Personality, 41, 1119-1160. doi:10.1016/j.jrp.2007.02.002

DeYoung, C. G., Quilty, L. C., \& Peterson, J. B. (2007). Between facets and domains: 10 aspects of the Big Five. Journal of Personality and Social Psychology, 93, 880-896. doi:10.1037/0022-3514.93.5.880

Donnellan, M. B., Lucas, R. E., \& Fleeson, W. (2009). Personality and assessment at age 40: Reflections on the past person-situation debate and emerging directions of future person-situation integration (Special issue). Journal of Research in Personality, 43, 117-290. doi:10.1016/j.jrp.2009.02.010 
Duckitt, J., Callaghan, J., \& Wagner, C. (2005). Group identification and outgroup attitudes in four South African ethnic groups: A multidimensional approach. Personality and Social Psychology Bulletin, 31, 633-646. doi:10.1177/0146167204271576

Eaton, L., \& Louw, J. (2000). Culture and self in South Africa: Individualism-collectivism predictions. The Journal of Social Psychology, 140, 210-217. doi:10.1080/00224540009600461

Funder, D. C. (2008). Person, situations, and person-situation interactions. In O. P. John, R. W. Robins, \& L. A. Pervin (Eds.), Handbook of personality: Theory and research (pp. 568-580). New York, NY: Guilford Press.

Gaertner, L., Sedikides, C., Vevea, J. L., \& Iuzzini, J. (2002). The “I," the “we,” and the "when": A meta-analysis of motivational primacy in self-definition. Journal of Personality and Social Psychology, 83, 574-591. doi:10.1037//0022-3514.83.3.574

Georgas, J., Van de Vijver, F. J. R., \& Berry, J. W. (2004). The ecocultural framework, ecosocial indices, and psychological variables in cross-cultural research. Journal of Cross-Cultural Psychology, 35, 74-96. doi:10.1177/0022022103260459

Heine, S. J., \& Buchtel, E. E. (2009). Personality: The universal and the culturally specific. Annual Review of Psychology, 60, 369-394. doi:10.1146/annurev.psych.60.110707.163655

Henrich, J., Heine, S. J., \& Norenzayan, A. (2010). The weirdest people in the world? Behavioral and Brain Sciences, 33, 61-135. doi:10.1017/S0140525X0999152X

Hicks, L. E. (1970). Some properties of ipsative, normative and forced-choice normative measures. Psychological Bulletin, 74, 167-184. doi:10.1037/h0029780

John, O. P., Naumann, L. P., \& Soto, C. J. (2008). Paradigm shift to the integrative Big Five taxonomy: History, measurement, and conceptual issues. In O. P. John, R. W. Robins, \& L. A. Pervin (Eds.), Handbook of personality: Theory and research (3rd ed., pp. 114-158). New York, NY: The Guilford Press. 
Kanagawa, C., Cross, S. E., \& Markus, H. R. (2001). Who am I? The cultural psychology of the conceptual self. Personality and Social Psychology Bulletin, 27, 90-103. doi:10.1177/0146167201271008

Kashima, Y. (2001). Culture and social cognition: Toward a social psychology of cultural dynamics. In D. Matsumoto (Ed.), The handbook of culture and psychology (pp. 325360). New York, NY: Oxford University Press.

Kashima, Y., \& Kashima, E. S. (2003). Individualism, GNP, climate, and pronoun drop: Is individualism determined by affluence and climate, or does language use play a role? Journal of Cross-Cultural Psychology, 34, 125-134. doi:10.1177/0022022102239159

Kashima, Y., Kashima, E. S., Kim, U., \& Gelfand, G. (2006). Describing the social world: How is a person, a group, and a relationship described in the East and the West. Journal of Experimental Social Psychology, 42, 388-396. doi:10.1016/j.jesp.2005.05.004

Liberman, N., Trope, Y., \& Stephan, E. (2007). Psychological distance. In A. W. Kruglanski \& E. T. Higgins (Eds.), Social psychology: Handbook of basic principles (2nd ed., pp. 353-381). New York, NY: Guilford Press.

Ma, V., \& Schoeneman, T. J. (1997). Individualism versus collectivism: A comparison of Kenyan and American self-concepts. Basic and Applied Social Psychology, 19, 261273. doi:10.1207/s15324834basp1902_7

Maass, A., Karasawa, M., Politi, F., \& Suga, S. (2006). Do verbs and adjectives play different roles in different cultures? A cross-linguistic analysis of person representation. Journal of Personality and Social Psychology, 90, 734-750. doi:10.1037/00223514.90 .5 .734

Markus, H. R., \& Kitayama, S. (1998). The cultural psychology of personality. Journal of Cross-Cultural Psychology, 23, 63-87. doi:10.1037/0033-295X.98.2.224

Matsumoto, D., Yoo, S. H., Fontaine, J., \& 56 Members of the Multinational Study of Cultural Display Rules. (2009). Hypocrisy or maturity? Culture and context differentiation. European Journal of Personality, 23, 251-264. doi:10.1002/per.716 
McCrae, R. R., \& Allik, J. (Eds.). (2002). The five-factor model of personality across cultures. New York, NY: Kluwer Academic/Plenum.

McCrae, R. R., Terracciano, A., \& 78 Members of the Personality Profiles of Cultures Project. (2005). Universal features of personality traits from the observer's perspective: Data from 50 cultures. Journal of Personality and Social Psychology, 88, 547-561. doi:10.1037/0022-3514.88.3.547

Meiring, D., Van de Vijver, A. J. R., Rothmann, S., \& Barrick, M. R. (2005). Construct, item, and method bias of cognitive and personality measures in South Africa. SA Journal of Industrial Psychology, 31, 1-8.

Mendoza-Denton, R., \& Mischel, W. (2007). Integrating system approaches to culture and personality: The cultural cognitive-affective processing system. In S. Kitayama \& D. Cohen (Eds.), Handbook of cultural psychology (pp. 175-195). New York, NY: Guilford Press.

Mischel, W., \& Shoda, Y. (1995). A cognitive-affective system theory of personality: Reconceptualizing situations, dispositions, dynamics, and invariance in personality structure. Psychological Review, 102, 246-268. doi:10.1037/0033-295X.102.2.246

Nel, J. A., Valchev, V. H., Rothmann, S., Van de Vijver, F. J. R., Meiring, D., \& De Bruin, G. P. (2012). Exploring the personality structure in the 11 languages of South Africa. Journal of Personality, 80, 915-948. doi:10.1111/j.1467-6494.2011.00751.x

Nisbett, R. E., Peng, K., Choi, I., \& Norenzayan, A. (2001). Culture and systems of thought: Holistic versus analytic cognition. Psychological Review, 108, 291-310. doi:10.1037//0033-295X.108.2.291

Oishi, S., Diener, E., Scollon, C. N., \& Biswas-Diener, R. (2004). Cross-situational consistency of affective experiences across cultures. Journal of Personality and Social Psychology, 86, 460-472. doi:10.1037/0022-3514.86.3.460

Peng, K., Ames, D. R., \& Knowles, E. D. (2001). Culture and human inference: Perspectives from three traditions. In D. Matsumoto (Ed.), The handbook of culture and psychology (pp. 245-264). New York, NY: Oxford University Press. 
Pronin, E. (2008). How we see ourselves and how we see others. Science, 320, 1177-1180. doi:10.1126/science.1154199

Rhee, E., Uleman, J. S., Lee, H. K., \& Roman, R. J. (1995). Spontaneous self-descriptions and ethnic identities in individualistic and collectivistic cultures. Journal of Personality and Social Psychology, 69, 142-152. doi:10.1037/0022-3514.69.1.142

Roccas, S., Sagiv, L., Schwartz, S. H., \& Knafo, A. (2002). The big five personality factors and personal values. Personality and Social Psychology Bulletin, 28, 789-801. doi:10.1177/0146167202289008

Saucier, G., \& Goldberg, L. R. (2001). Lexical studies of indigenous personality factors: Premises, products, and prospects. Journal of Personality, 69, 847-879. doi:10.1111/1467-6494.696167

Schmitt, D. P., Allik, J., McCrae. R. R., Benet-Martínez, V., et al. (2007). The geographic distribution of Big Five personality traits: Patterns and profiles of human selfdescription across 56 nations. Journal of Cross-Cultural Psychology, 38, 173-212. doi:10.1177/0022022106297299

Sedikides, C., Gaertner, L., \& Vevea, J. L. (2005). Pancultural self-enhancement reloaded: A meta-analytic reply to Heine. Journal of Personality and Social Psychology, 89, 539551. doi:10.1037/0022-3514.89.4.539

Seekings, J. (2008). The continuing salience of race: Discrimination and diversity in South Africa. Journal of Contemporary African Studies, 26, 1-25. doi:10.1080/02589000701782612

Semin, G. R., \& Fiedler, K. (1991). The linguistic category model, its bases, applications and range. In W. Stroebe \& M. Hewstone (Eds.), European review of social psychology (Vol. 2, pp. 1-30). Chichester, United Kingdom: Wiley.

Shweder, R. A., \& Bourne, E. J. (1984). Does the concept of the person vary cross-culturally? In R. A. Shweder \& R. A. LeVine (Eds.), Culture theory: Essays on mind, self, and emotion (pp. 158-199). Cambridge, England: Cambridge University Press. 
Spencer-Rodgers, J., Williams, M. J., \& Peng, K. (2010). Cultural differences in expectations of change and tolerance for contradiction: A decade of empirical research.

Personality and Social Psychology Review, 14, 296-312. doi:10.1177/1088868310362982

Statistics South Africa (2001). Census 2001: Key results. http://www.statssa.gov.za

Tabachnick, B. G., \& Fidell, L. S. (2007). Using multivariate statistics (5th ed.). Boston, MA: Allyn \& Bacon.

Triandis, H. C. (2001). Individualism-collectivism and personality. Journal of Personality, 69, 907-924. doi:10.1111/1467-6494.696169

Triandis, H. C., \& Suh, E. M. (2002). Cultural influences on personality. Annual Review of Psychology, 53, 133-160. doi:10.1146/annurev.psych.53.100901.135200

Valchev, V. H., Nel, J. A., Van de Vijver, F. J. R., Meiring, D., De Bruin, G. P., \& Rothmann, S. (in press). Similarities and differences in implicit personality concepts across ethnocultural groups in South Africa. Journal of Cross-Cultural Psychology. doi:10.1177/0022022112443856

Valchev, V. H., Van de Vijver, F. J. R., Nel, J. A., Rothmann, S., Meiring, D., \& De Bruin, G. P. (2011). Implicit personality conceptions of the Nguni cultural-linguistic groups of South Africa. Cross-Cultural Research, 45, 235-266. doi:10.1177/1069397111402462

Van de Vijver, F. J. R., \& Leung, K. (2001). Personality in cultural context: Methodological issues. Journal of Personality, 69, 1007-1031. doi:10.1111/1467-6494.696173

Watkins, D., Adair, J., Akande, A., Cheng, C., Fleming, J., Gerong, A., ... Yu, J. (1998). Cultural dimensions, gender, and the nature of self-concept: A fourteen-country study. International Journal of Psychology, 33, 17-31. doi:10.1080/002075998400583

Watkins, D., \& Gerong, A. (1997). Culture and spontaneous self-concept among Filipino college students. The Journal of Social Psychology, 137, 480-488. doi:10.1080/00224549709595464 


\section{Footnotes}

${ }^{1 .}$ In preliminary analyses we examined the language subgroups within the Black group, Coloureds, and Indians separately. The proportions of traits were the following: Sotho-Tswana (.36), Nguni (.36), Tsonga and Venda (.36), Coloureds (.51), Indians (.55), in contrast to Whites (.69); the proportions of contextualized responses were: Sotho-Tswana (.36), Nguni (.33), Tsonga and Venda (.32), Coloureds (.24), Indians (.23), in contrast to Whites (.15). The proximity of the values between the Black groups as well as between Coloureds and Indians justified merging the groups into Blacks and Coloureds and Indians, respectively.

2. There were group differences in the average number of descriptions per participant: 40 in Blacks, 62 in Coloureds and Indians, and 63 in Whites. To test for the effects of these differences, we removed the last $36 \%$ of each target person's descriptions in the Coloured and Indian and the White group (leaving at least one description per target person), bringing the average number to 40 per participant for these two groups, and re-ran the main analyses of this study. The total proportion of traits went up by .02 (to .56) for Coloureds and Indians and by .03 (to .72) for Whites, and that of context-free descriptions, by .02 for both groups (to .78 and .87 , respectively). All major effects discussed in this article were essentially unchanged. We report the results from the complete data set to use all the available information.

3. There were cross-cultural differences in the category of peripheral to personality descriptions, which was excluded from all analyses of this study: The category had a proportion of .07 in Blacks and .03 in Coloureds and Indians as well as Whites when all categories were included. However, this category accommodates heterogeneous elements like physical descriptions, occupation, and other biographical information, 
so it cannot be considered as a systematic addition to the categories of social roles and identities.

4. We assigned the descriptions of a disliked person and a person opposite to the participant to one of the social distance categories if the content of the descriptions indicated unambiguously that they referred to one of the targets in these categories (family member, neighbor, etc.). For some of the descriptions, the target was not evident from the interview transcriptions. The total number of descriptions employed in this analysis $(46,658)$ is hence smaller than the grand total $(53,069)$.

${ }^{5 .}$ Because not all descriptions could be unambiguously assigned to one of the nine clusters, the total number of descriptions employed in this analysis $(49,190)$ is smaller than the grand total $(53,069)$.

6. It could be argued that the increased contextualization of the social-relational concepts was due specifically to relational contextualization. To test this, we repeated the analyses of contextualization across personality domains, this time treating relationally contextualized responses as context-free. The overall results were similar to those with the complete contextualization measure, with smaller effects. Contextualized responses were still overrepresented in the communal category and in Facilitating, but that was no longer the case for Relationship Harmony and SoftHeartedness. In summary, relational contextualization accounted for a part but not all of the association of contextualization with personality domains. 